\title{
Prostate cancer - statistical analysis data in a 5 year period in Shtip, Republic of North Macedonia
}

\author{
Zhu Jihe ${ }^{1}$, Arsovska Blagica ${ }^{1,2}$ and Kozovska Kristina 1,3,* \\ ${ }^{1}$ Faculty of Medical Sciences, University Goce Delchev, Shtip, Republic of Macedonia. \\ ${ }^{2}$ Institute of Biology, Faculty of Natural Sciences and Mathematics, Skopje, Republic of Macedonia. \\ ${ }^{3}$ Medicine Faculty, St. Cyril and Methodius University of Skopje, Republic of Macedonia.
}

Publication history: Received on 27 March 2020; revised on 06 April 2020; accepted on 06 April 2020

Article DOI: https://doi.org/10.30574/wjarr.2020.6.1.0083

\begin{abstract}
The prostate is a small gland that lies beneath the bladder and is present only in men. Prostate cancer, one of the most common malignancies that occurs in men over 50 years old. More than $95 \%$ of prostatic tumors are adenocarcinomas. For the purposes of this paper was used data from the Institute for Public Health -Shtip, Republic of North Macedonia in the period of 2014 to 2018 . The results shows that the total number of patients with prostate cancer for this period of 5 years is 1578. The most common age of prostate changes is between the ages of $65-74$, but a large number of individuals are also noticed between the ages of 45 and 64. In 2014 most of the cases are at age group of 55 to 65 with 121 patients, also in 2015 this age group is most affected with 135 patients. In 2016 there is a large percentage of new cases between the ages of 65-74 or 166. Analysis of the newly discovered cases in 2017 shows the highest number of new cases between the ages of 65-74. In 2018 there is no significant difference, 166 newly discovered between the ages of 65-74 which is also the age group with the most cases in the entire 5 year study period. In Macedonia, about 1250 new cases of prostate cancer are discovered per year.
\end{abstract}

Keywords: Statistics; Prostate; Cancer; Macedonia

\section{Introduction}

The prostate is a small gland that lies beneath the bladder and is present only in men. Prostate cancer is a one of the most common types of cancer in men. Prostate cancer begins when prostate cells start to grow uncontrollably. Prostate cancer while in early healing phase rarely gives symptoms. This is because prostate cancer does not affect the urethra until it is large enough. If it grows and spreads outside the prostate it is advanced stage cancer and can cause: pain and burning in the urine, frequent urination and difficulty in urinating, blood in the urine, lower back pain and hips. If cancer spreads to the spine and compresses the spinal cord, it may have: • weakness in the legs, urinary incontinence, fecal incontinence Almost all prostate carcinomas are adenocarcinomas. These cancers develop from gland cells (the cells that make the fluid of the prostate that is added to the sperm). Other types of prostate cancer include: Sarcoma, small cell carcinomas, neuroendocrine tumors (except small cancers), transitional cell carcinomas. These other types of prostate cancer are rare. The main risk factors for prostate cancer are age as well as the family history of prostate cancer, diet, lifestyle, smoking, stress, drinking alcohol.

In prostate cancer as in all malignant diseases, histological stage is very important for the prognosis of the disease. The standardized international TNM system is used to determine the stage of prostate cancer and shows how wide it is. To show how fast prostate cancer can grow, a system called Glycogen Result is used. It is obtained by adding a degree between 3 and 5 to the two most common types of tissue. Then those two degrees are added together to get an final result of 10 .

\footnotetext{
* Corresponding author: Kozovska Kristina
} 
The treatment is different for early and advanced prostate cancers. If the cancer is localized and small and, it is managed by one of the following therapies: Waiting or monitoring: Blood PSA levels are checked regularly, but there is no immediate action. Radical prostatectomy, brachytherapy, formal radiation therapy, Intensity modulated radiation therapy. Advanced cancer is more aggressive and spreads further through the body. The effect of androgen is reduced by a hormonal therapy called androgen deprivation therapy (ADT) or androgen suppression therapy. Androgens are male hormones that can stimulate the growth of cancer. Radical prostatectomy is currently not an option for advanced cases because it does not treat cancer that has spread to other parts of the body. [1-6]

\section{Material and methods}

In this research were taken data from the Center of Public Health in Shtip, Republic of Macedonia, for the region of Shtip in the period from 2014 to 2018, for patients diagnosed with prostate cancer. Patients of different ages who were diagnosed with any prostate change are included. The aim of the research is to determine if the number of cases of prostate cancer is increasing and which age group is most prevalent. The results are shown graphically and explained accordingly.

\section{Results and discussion}

The following diagram shows the percentage of prostate cancer in the region of Stip from 2014 to 2018. It can be noticed that there is no significant difference in the newly discovered cases in the studied years.

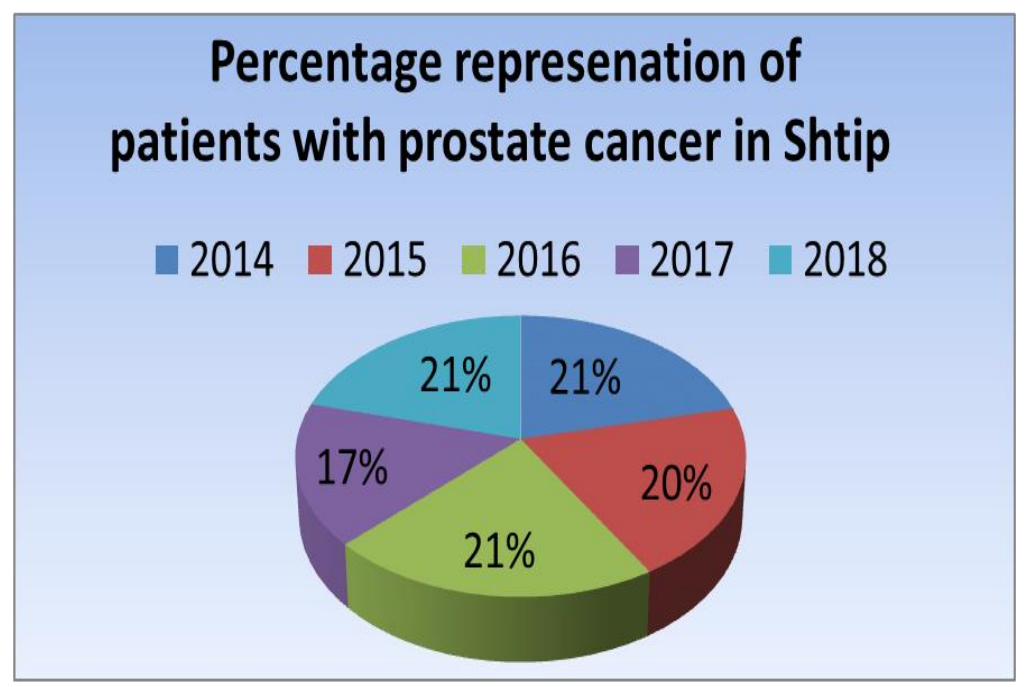

Figure 1 Percentage representation of patients with prostate cancer in Shtip in period from 2014 to 2018

According to this report it can be noticed that in 2014 there were 337 cases, most of them between the ages of 55-64 with 121 cases, and thereafter an insignificant difference can be noticed between the ages of 65-74 with 106 cases. Compared with previously reported results, it can be noticed that prostate changes were not occurred in persons under 35 years of age, a small number, ie 12 cases were noticed at the age of 35-44 years.

In 2015, compared to 2014, there were no significant changes in the number of newly discovered cases. Most of the cases are at the age between 55-64 with 135 cases and 116 cases aged over 74 years. As in the previous year, there were no cases of men under 35 years of age.

In 2016, there is a large percentage of new cases between the ages of 65-74, ie 166 cases.While a significantly lower number of cases was noticed in patients over 74 years than in the previous year with 67 newly discovered. In this year, no new cases have been noticed in men under 45, but in the age group from 45 to 54 are noticed 34 cases.

The analysis of the newly discovered cases in 2017 shows highest number of new cases between the ages of 65-74. It is important to report two cases at the age between 25-27. Compared to the previous year, a smaller number of new cases were noticed between the ages of 45 and $54-22$ cases. 
In 2018 compared to the previous years it is important to report 3 cases of prostate changes in children aged 7-14 years. While at other age groups there is no significant difference. There are 166 newly discovered between the ages of 65-74 which is also the age group with the most cases in the entire 5 year study period.

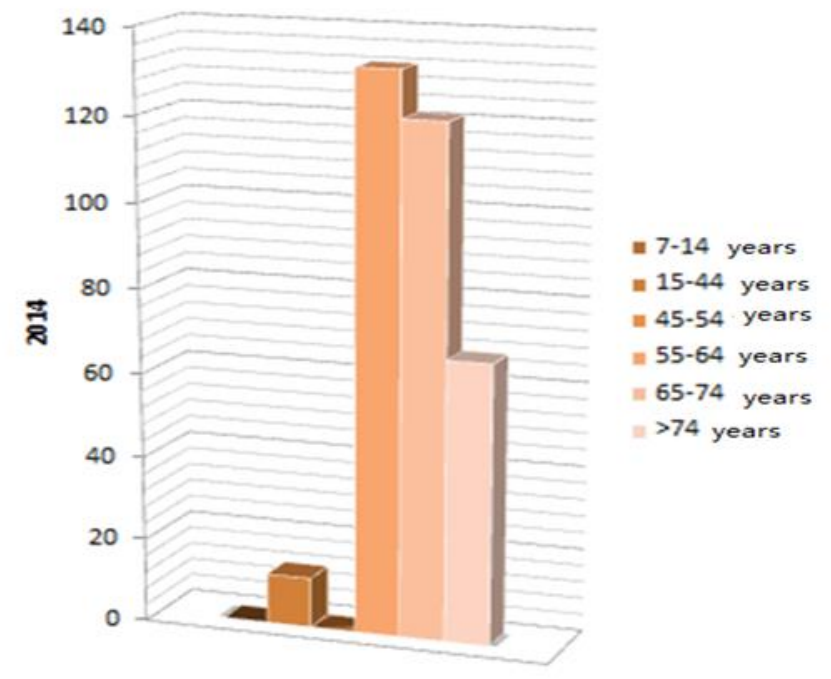

Figure 2 Representation of patients with prostate cancer in Shtip in period by 2014

On figure 2 are shown the results from 2014. Most of the cases were in the age group 55-64, ie 121 recorded cases. 106 cases are recorded between the ages of 65-74.

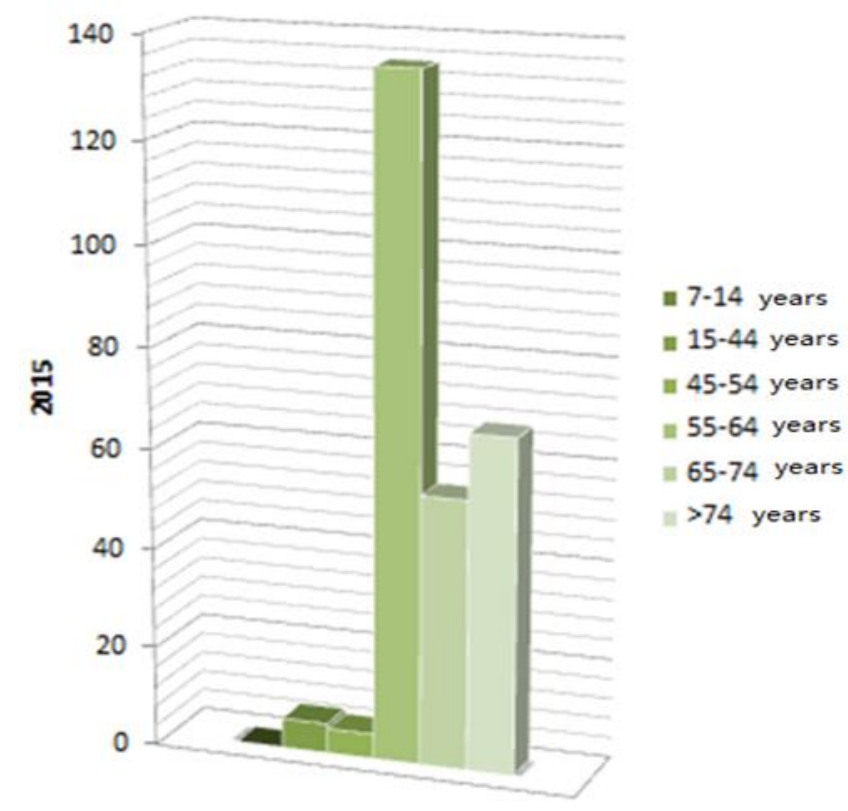

Figure 3 Representation of patients with prostate cancer in Shtip in period by 2015

On figure 3 are shown the results from 2015. Most of the cases were in the age group 55-64 years, ie. 125 recorded cases. 49 cases were recorded between the ages of 65-74. 


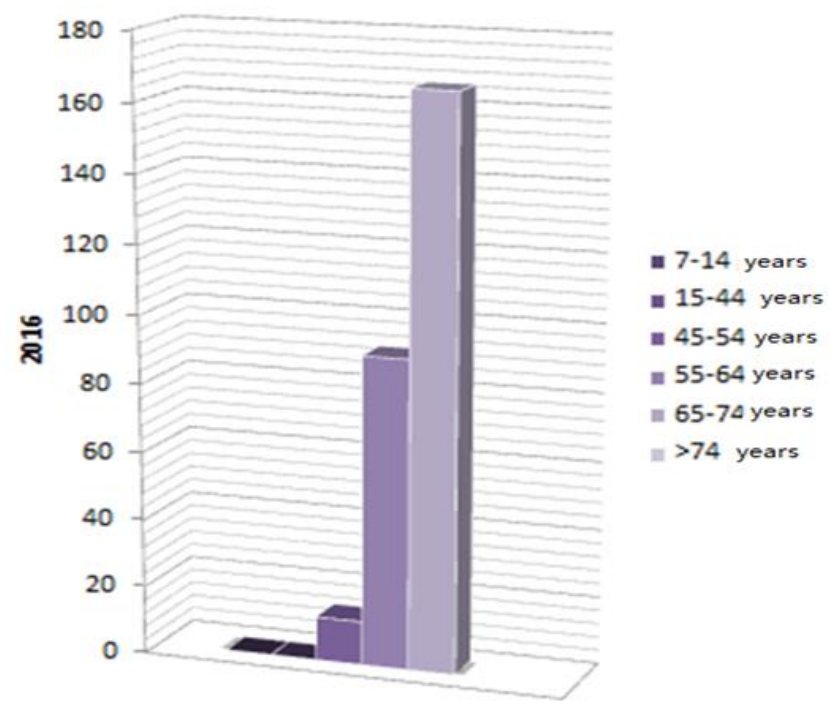

Figure 4 Representation of patients with prostate cancer in Shtip in period by 2016

On figure 4 are shown the results from 2016. Most cases were in the age group of 55-74 years, ie. 154 recorded cases. 84 cases were recorded between the ages of 55-64.

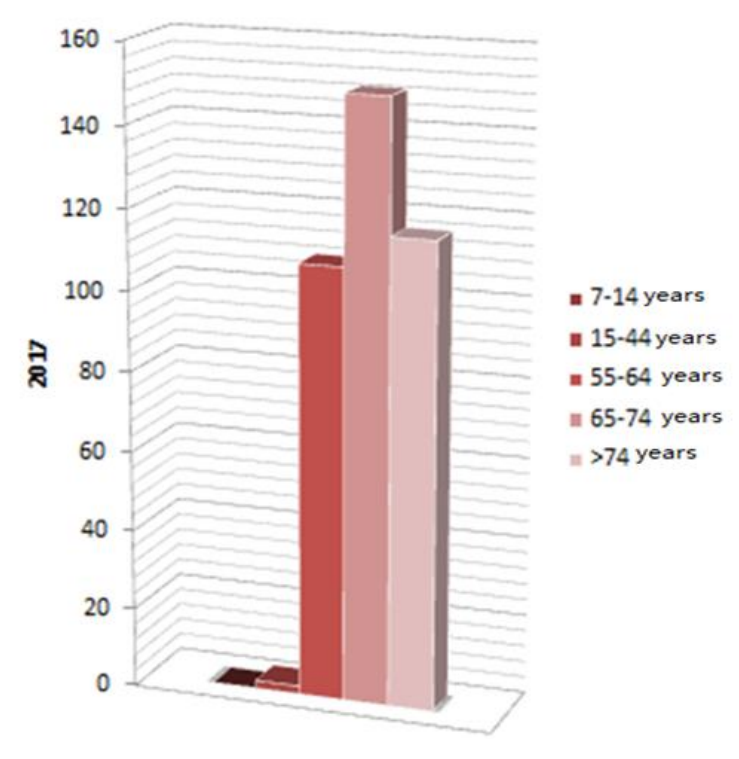

Figure 5 Representation of patients with prostate cancer in Shtip in period by 2017

On figure 5 are shown the results from 2017. Most cases were in the age group of 65-74 years, ie. 136 recorded cases. 101 cases were recorded between the ages of 55-64.

On figure 6 are shown results from 2018. Most cases were in the age group of 65-74 years, ie. 155 recorded cases. 109 cases were recorded at age over 74 . 


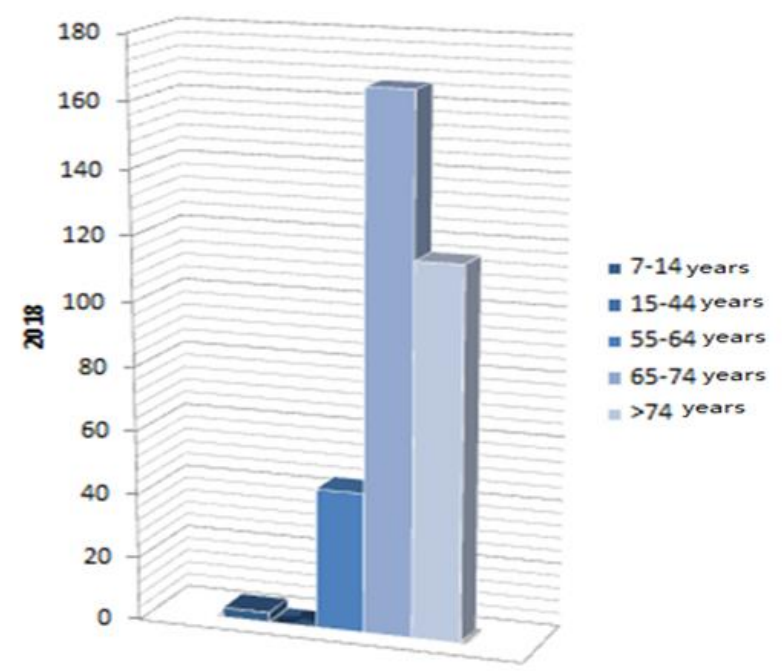

Figure 6 Representation of patients with prostate cancer in Shtip in period by 2018

\section{Conclusion}

About 1250 new cases of prostate cancer are discovered in Macedonia per year. Prostate cancer is usually not diagnosed in the early stages of the disease, because it usually does not give any symptoms. Therefore, preventive urologic examinations of the prostate are of great importance. The most common age of prostate changes is between the ages of $65-74$, but a large number of individuals are also noticed between the ages of 45 and 64 . Because of that prevention is needed in people over the age of 40 in order to prevent more serious complications.

\section{Compliance with ethical standards}

\section{Disclosure of conflict of interest}

The authors declare that there is no conflict of interest.

\section{References}

[1] Nadezhda Hristova Djordjevic, Anica Kargovska Klisarova, Kostadina Korneti Pekevska. Anatomy man - Karlica. Skopje (2001).

[2] Brinkman M, Reulen RC, Kellen E, Buntinx F and Zeegers MP. (2006). Are men with low selenium levels at increased risk of prostate cancer? Eur J Cancer, 42(15), 2463-71.

[3] Andriole GL, Crawford ED, Grubb RL, 3rd, Buys SS, Chia D, Church TR, et al. (2009). Mortality results from a randomized prostate-cancer screening trial. N Engl J Med, 360(13), 1310-9.

[4] Lawrentschuk N, Trottier G, Kuk C and Zlotta AR. (2010).Role of surgery in high-risk localized prostate cancer. Curr Oncol, 17 Suppl 2, S25-32.

[5] Aus G, Paarsons K, Shmid HP, Lobel B, Chapple CR, Hanuš T, et al. (2008). The Europen Association of Urology Guidelines.EAU, 3-60.

[6] Petrioli R, Fiaschi AI, Francini E, Pascucci A and Francini G. (2008). The role of doxorubicin and epirubicin in the treatment of patients with metastatic hormone-refractory prostate cancer. Cancer Treat Rev, 34(8), 710-8.

\section{How to cite this article}

Zhu J, Arsovska B and Kozovska K. (2020). Prostate cancer - statistical analysis data in a 5 year period in Shtip, Republic of North Macedonia. World Journal of Advanced Research and Reviews, 6(1), 77-81. 